\title{
Entering the world of sex offenders: an exploration of offending behaviour patterns of those with both internet and contact sex offences against children
}

\author{
Deniz Aslan, Robert Edelmann, Diane Bray and Marcia Worrell
}

\author{
Dr Deniz Aslan is a Consultant \\ Psychologist and Lecturer, \\ based at Department of \\ Psychology, Roehampton \\ University, London, UK and \\ Langford Clinic, \\ East Sussex, UK. \\ Robert Edelmann is a \\ Professor of Forensic and \\ Clinical Psychology, \\ Dr Diane Bray is the Head of \\ Department and Dr Marcia \\ Worrell is a Principal Lecturer, \\ all are based at Department of \\ Psychology, Roehampton \\ University, London, UK.
}

\begin{abstract}
Purpose - The relationship between accessing indecent images online and the perpetration of contact child sex offences remains unclear. The purpose of this paper is to provide a better understanding of the offence process of offenders who have both such convictions.

Design/methodology/approach - A total of eight semi-structured interviews were conducted with older adult males who had downloaded indecent images and also had a history of contact sex offences against children. Data analysis involved thematic coding based on guidelines suggested by Braun and Clarke (2006).

Findings - Themes which emerged suggest some similarities (offence process behaviours), but also some differences (developmental factors) between the eight offenders. Data relevant to developmental factors formed two primary themes: childhood attachment difficulties and experiences of childhood abuse, both of which appeared to influence the offence process. Escalating factors generated a further three themes: adult relationships, personality problems and substance use. Five main categories also emerged with regard to offence behaviours: sexually deviant interests, lack of self-control, opportunity, the role of the internet (availability, easy access and anonymity), and cognitive distortions (justifications: interest in challenge and sexual frustration; denial: accidental access and denial of a victim, normalisation; blame: blame on the victim, new technologies and authorities and blame on other factors; and minimisation).

Practical implications - A better understanding of the offence process would inform clinical practice with such offenders and aid in the process of prevention.

Originality/value - This is the first research to date which explores the rationale provided for their
\end{abstract} behaviour by those convicted of both internet and contact child sex offences.

Keywords Child sex offenders, Offence pathways, The role of internet

Paper type Research paper

\section{Introduction}

To date, there is limited research evaluating the offending patterns of sex offenders who have convictions for both the possession of indecent images (internet offenders) and contact offences against children. Research specifically addressing the key factors which might influence the offence process of such offenders is practically non-existent. There are though a number of theories, both with regard to general theories of crime and more specifically in relation to sex offending, which seek to explain offence pathways.

Some of the most basic theories emphasise developmental factors or attachment difficulties. There is though not a clear and straightforward association between the presence of specific developmental factors and internet sex offences, with early childhood attachment difficulties 
and maltreatment only providing a partial explanation for sexually deviant behaviours of some, but not all internet sex offenders (Sheldon and Howitt, 2007). However, developmental trajectories or individual pathways may be forged by building blocks of behaviours and experiences, which influence patterns of adult sex offending against children (Connolly, 2004).

General theories of crime provide a useful starting point when considering plausible explanations for sex offending against children. Lack of self-control is assumed to be the broadest and most important factor in the process of offending (Baumeister and Boden, 1998). This theory describes those who commit sexual offences (like those who commit any other offence) as versatile offenders who engage in many different types of crime and antisocial behaviours (Gottfredson and Hirschi, 1990).

Developmental theories also provide a possible explanation of sexual offending. Age of onset and persistence of delinquency are key features that determine severity and continuity of antisocial behaviours and its association with psychosocial and individual problems both in relation to general criminal behaviour and sexually motivated crime (Fergusson et al., 1996; Jeglum-Bartusch et al., 1997). Such theories have been evaluated by examining how behaviour patterns change in relation to the time of onset and type of offending behaviour, and the rate at which offences are committed, linking different offence trajectories to different aetiological factors (Moffitt, 1993; Patterson and Yoerger, 2002; Lahey and Waldman, 2003). While general theories of crime and developmental theories offer some degree of insight neither are able to fully explain multiple offences against children. General theories of crime provide a useful starting point in explaining these offences but self-control appears to be a trait that exists along a continuum; it can be directly modified and may not consistently predict sexual offending behaviours. In support of a developmental theory of offending behaviour, studies describing offence trajectories are of particular relevance when considering chronic offenders whose criminal career often begins at an early age and persists into adulthood. Moffitt's (1993) theory appears to be applicable to offenders who have both internet and contact convictions. However, this might only account for changes and continuities in terms of severity of offending (i.e. escalation and de-escalation). Those sex offenders who commit internet-contact offences against children may warrant a more specific explanatory framework.

Finkelhor (1984) provided the first multifactorial theory as to how individual psychological characteristics and broader socialisation combine in order to facilitate child abuse. This theory described four stages (motivation to sexually abuse; overcome internal inhibitors; overcome external inhibitors and the resistance of the child) that precede sexual offending, and explains some of the diverse characteristics among sex offenders. Although, the theory has strongly influenced clinical work with sex offenders, there is conceptual overlap between stages, and its applicability to internet-contact offenders remains unclear. It does not account for why, in certain circumstances, non-sexual needs are expressed in a sexual way. For example, emotional congruence where offenders turn to children because they are less threatening is very similar to developmental blockage, where offenders unable to meet their need for intimacy with an adult turn to children. There is also a similarity between disinhibition and overcoming internal inhibitions. With regards to internet-contact offending, Finkelhor's (1984) Precondition model does not fully explain this. The first three stages could be related to internet offenders but the question then becomes what motivates the offender to continue to stage 4 or in some instances to stop before the final stage. For example, in viewing indecent images of children overcoming the resistance of a child is not necessarily a pre-cursor to this offence.

Wolf (1989) and Eldridge's (1998) cycle of sex offending was based on the assumption that experiences of childhood maltreatment function as "potentiators" to the development of sexually deviant behaviour by dissolving inhibitions which would usually prevent against sexual deviance. However, while such models provide a useful framework around which to structure treatment, in particular explaining how the offender becomes stuck in a negative cycle of offending, they are too restrictive to fully describe the process of internet-contact offences.

Ward and Hudson's (1998) self-regulation model expanded upon earlier models by arguing how child sex offenders guide their own actions in different ways. Their four offence pathways described the offenders' approach towards the sexually deviant behaviour (avoidance or 
approach) during the planning stage of the offence process, the strategies adopted to achieve their goals (passive, active, explicit or automatic) and also the adoption of one of three self-regulation styles (under regulation, mis-regulation and effective regulation). In comparison to previous theories, Ward and Hudson's (1998) self-regulation model has significant advantages. This model provides both a more individualistic approach and yet also captures the diversity of the offence process. However, it is unclear whether such theories relating to general sex offending are also applicable to perpetrators of child abuse.

Extending on the above, Ward and Siegert's (2002) pathways model suggests there are multiple pathways leading to sexual offending and that each pathway involves a core set of dysfunctional psychological mechanisms that cause specific outcomes. The model identifies five etiological pathways: intimacy deficits, deviant sexual scripts, emotional dysregulation, anti-social cognitions and multiple dysfunctional mechanisms. The first etiological pathway, intimacy deficits, refers to offenders who are hypothesised to possess normal sexual scripts and only offend at specific times (e.g. at times of prolonged loneliness, rejection, or if their adult relationships are compromised or unsatisfactory). The second etiological pathway, deviant sexual scripts, refers to offenders who have subtle distortions of sexual scripts and dysfunctional attachment styles (Ward et al., 1996), where interpersonal closeness is only achieved via sexual contact. The third etiological pathway, emotional dysregulation, refers to offenders who possess normal sexual scripts but have difficulties in the self-regulation of emotions (Thompson, 1994). The fourth etiological pathway, anti-social cognitions, refers to offenders who do not have distortions in their sexual scripts but possess general pro-criminal attitudes and beliefs and whose offending reflects this antisocial tendency. Finally, the fifth pathway, multiple dysfunctional mechanisms, refers to offenders who have distorted sexual scripts coinciding with dysfunctions in all of the other primary psychological mechanisms. Middleton et al. (2006) tested the applicability of this model on a sample of 72 male internet offenders with findings indicating that the majority of internet offenders fell into either the "intimacy deficits" category (38 per cent of the sample) or the "emotional dysregulation" category (35 per cent of the sample). Those with intimacy deficits accessed indecent images at times of loneliness and dissatisfaction whilst those with emotional dysregulation problems accessed indecent images of children as a mood-alleviating strategy. Because the results refer to deficits and distortions one unfortunate inference, which clearly few would argue for, is that these men are in some way "blameless" for their offending behaviour because they are somehow "defective". Furthermore, because data was generated from the National Probation Services standardised psychometric battery for the accredited Sex Offender Treatment Programmes (Beech et al., 1999), rather than interviews with actual internet offenders, it is difficult to assess whether salient additional, perhaps contradictory, information may have been lost.

Theories more specific to internet offending have provided some explanation of the offence process of multiple convictions and in particular the relationship between viewing indecent images and actual abuse of children. Based on a literature review, Quayle and Taylor's (2003) model provided an important step towards an understanding of problematic internet use and subsequent contact offending. Their model focused on six core areas (setting events, engaging with the internet, escalation of problematic internet use, offending behaviour, non- offending behaviour and process) that, when combined, could contribute to problematic internet use and subsequent contact offending. However, this model lacks specific evidence from clinical practice and without empirical research it is difficult to determine whether offenders who have convictions for both internet and contact child sex offences actually represent a subgroup of sex offenders distinguishable from those who only commit either contact or internet only offences.

\subsection{The present study}

There are a number of theories which provide some insight into the offence process but limited research focusing on the offending patterns of internet-contact child sex offenders. Understanding the offence process would make an important contribution to the literature, which would help to facilitate more effective treatment and management strategies for this population. The aim of this study, therefore, is to elicit information about how offenders with convictions for both internet and contact offences make sense of their offending behaviours and

PAGE 112 | JOURNAL OF FORENSIC PRACTICE $\mid$ VOL. 16 NO. 22014 
to explore the nature of the relationship between committing contact offences and viewing indecent images of children and to examine the extent to which these explanations fit with existing theories of the offence process.

\section{Method}

\subsection{Design}

A qualitative research methodology using a semi-structured interview schedule was used in this study. Qualitative interviews propose the construction of theory from verbal data and focus on an individual's subjective view of the inner world perspective that is not easily answered by quantitative methods (Orford, 1996; Willig, 2001). Such methods aim to explore a central research question rather than prove or disprove a preconceived idea. They are potentially very useful for exploring areas about which little is known (Gilbert, 1993) and offer a powerful and flexible tool for increasing knowledge about complex and heterogeneous variables. It is anticipated that adopting this approach would offer rich insight into those who have been convicted of both downloading and accessing indecent images of children as well as committing contact child sex offences.

\subsection{Participants}

A purposive sampling approach was used to identify participants, who had committed both contact and non-contact (i.e. internet-related) offences against children. Internet offences consisted of accessing, downloading, trading and/or making indecent images, or pseudo-images of children. Contact offences consisted of "hands-on" assaults, including indecent assault, unlawful intercourse, rape and buggery against children. Based on official records of convictions, eight offenders who were convicted of internet-related offences, but who had a past history of contact offending at the time of their index offence, were selected for the study. It is possible that they may have committed additional online offences prior to the contact offence. All participants were white British males aged 18 and over $(S D=7.11 ; M=54.87)$, and were on probation, supervised across Greater London Offender Management Units (for full details of the eight participants see Appendix).

\subsection{Procedure}

Participants were given a brief preliminary interview to outline the purpose of the research before agreeing to take part. The men were told that their participation in the study was voluntary and would not influence their progress through the Offender Management Units. There were no compensation or inducements provided to offenders for participating in the research. They were assured of confidentiality and anonymity, unless they disclosed specific information about a current risk to self or the public. All participants completed a consent form and were given standardised instructions. Each participant was allocated a unique code number known only to the researchers that was used to record and store information arising from the research. All offenders were seen at the Offender Management Units on a one-to-one basis with the lead author, the interviews lasting between one or two hours.

The questions in the semi-structured interview were designed to be non-threatening, sensitive and encouraging. A pilot interview was conducted to check for validity of interview questions. This was designed to gather information about personal background including histories of emotional, physical or sexual abuse as a child with the main questions focusing more on the different stages in the offending process. In order to maximise offenders' comfort in talking about issues related to their offending behaviour, they were initially asked general questions about their best memories of childhood, schooling and relationships. At the end of the interview, all participants were debriefed to counteract any possible distress that might have resulted from answering the questions. The researchers have adopted specific best-practice guidelines for the storage of different types of data, in strict accordance with the Data Protection Act 1998 and ethical guidelines stipulated by the British Psychological Society. Ethical approval was granted by both the University of Roehampton and the London Probation Service. Data from the interviews were captured by way of audio tape recording and completing research notes at the end of each interview. 


\section{Data analysis}

In order to facilitate data analysis, all interviews were tape recorded using audiotape and later transcribed into Word documents. Transcripts were then read and re-read in order to gain an overall understanding of offenders' views and experiences, to identify emerging themes and to develop a coding frame. Transcripts were read by different members of the research team, so that the analysis and coding frame could be refined through discussion. This was followed by data reduction in which all transcripts were coded using broad category codes and suggested possible interpretations. The transcripts were then grouped by broad category codes and then each case was examined and reconfigured for recurring common threads constantly comparing extracts case by case.

Data analysis involved a thematic coding analysis based on guidelines suggested by Braun and Clarke (2006). Thematic analysis can either identify the themes pertaining to a particular research question (deductive analysis) or it can identify themes that are observed across the entire data range (inductive analysis) (Braun and Clarke, 2006). Inductive thematic analysis occurs when the researcher observes themes from the data without having had a particular preconception of the various themes that would emerge. Deductive thematic analysis on the other hand, is guided by the researcher's particular thematic interest and seeks to analyse a specific area of the data. The authors used a deductive approach as this method facilitates the interpretation of identifiable themes and patterns of behaviour. The process involves five main stages based on the guidelines of a number of sources (Aronson, 1994; Braun and Clarke, 2006; Breakwell et al., 2000; Lambert and O'Halloran, 2008). These are detailed reading of the data quantity, identification of data sets, identification of initial themes from data sets, refinement of themes, and clustering themes into categories.

\section{Results}

The thematic analysis relevant to developmental factors formed two primary themes, which explored childhood attachment difficulties and experiences of childhood abuse, both of which appeared to influence the offence process. Attachment problems in adulthood, personality styles, and substance use were identified from the data as escalating factors contributing to the offence process. Explanations of participants' offence related behaviours generated a further five key themes: sexually deviant interest, lack of self-control, opportunity, the role of the internet and cognitive distortions. Selected quotations from the interviews are used both to illustrate and give support to each category.

\subsection{Developmental factors}

4.1.1 Childhood attachment difficulties. Themes relevant to participants' recollection of early childhood attachment difficulties formed two subcategories. This experience was either predominantly negative or positive, where participants experienced parental neglect, rejection, prolonged absence or dysfunctional parenting style, or experienced family cohesion, stability and positive relationships with primary caregivers.

Positive childhood attachment. In order to present the shared experiences of participants, three offenders' childhoods were free from poor attachment and described their childhoods as "happy":

$[\ldots]$ If there was something that tripped this off you know. If I was abused you know [...] If I had a poor family background [...] If I didn't have supportive parents then you could say possibly that this was the case and what have you. None of these happened to me [...] I had very supportive parents [...] no abuse $[\ldots]$ I had a very good childhood and very fortunate in many other things. My parents were the most wonderful that you could every think [...] (David).

In some instances at least, attachment difficulties may not be the significant feature of offending behaviour for some sex offenders. It is possible that their offending is influenced by non-familial abusive childhood experiences or bound up with other escalating factors such as social difficulties, adult relationships, personality problems or substance abuse. 
Negative childhood attachment. The childhoods of other offenders were frequently problematic, lacking parental nurturance and with periods of separation from parents:

When my mother put me in the orphanage I was six years old I said to her she is dead in my mind [...] (Ed). When I was young [...] ah one minute we were living in Morecombe, then we were living in Lancaster, then living with Nana, then living with my Aunty [...] and I thought there was nobody else that [...] to turn to [...] no real parents [...] (Harry).

Early relationships with parents, whether positive or negative, provide a model or template for future behaviours (Beech and Mitchell, 2005). Such experiences may not affect development in a single way but generate a way of "looking at the world" through schemata (Mann and Beech, 2003), or implicit theories (Ward and Keenan, 1999) that contribute to the evolution of perception, arousal and behavioural impetus which predispose some to act out sexually with children.

4.1.2 Abusive childhood experiences. Three subthemes of abusive childhood experiences were identified: emotional, physical and sexual. These subcategories were not mutually exclusive, and some participants reported experiencing more than one type of abuse. Only one participant described his early childhood experiences as non-abusive.

Emotional abuse. Childhood emotional abuse is viewed as the core issue in childhood maltreatment because this theme unifies the dynamics that underline the destructive power of all forms of child abuse and neglect. The most frequent form of this was being bullied at school and feeling isolated as a consequence of lack of confidence in peers and displacement:

There were bullies in my, my childhood, like I imagine there are bullies in everyone else's [...] I was eleven, you know (pause) fool [... I I was fat and I had little round glasses and I couldn't run, so people would bully me [...] (Alex).

In some cases, as in the following example, participants appeared to have normalised their abusive childhood experiences. This would seem to resonate with Briggs and Hawkins (1996), who suggested that victims who normalise abuse experiences in their childhoods are more likely to become abusers than other victims, even when the abuse is perceived as harmful or damaging:

[...] we build boundaries, lines that we cannot cross and there are things that teach us these boundaries. As a child when I was growing up those boundaries weren't put in place for me or they were put in the wrong place. It was normally [...] would have to go and sit on my bed put whatever toys I had to put them at the bottom of my bed and I was not allowed to touch them. I was not allowed to read, I was not allowed to play. Just sit on my bed. That was normally the punishment. No physical punishment. It was what you might call emotional [...] I would live in my bedroom basically, unless my dad was at work (Fred).

Physical abuse. Three of the respondents had experienced quite severe, systematic physical abuse by their biological mother or stepfathers:

My mother was very violent towards me and my brother. We used to get the shoe or the belt. She'd throw things at me [...] Oh she was violent to me [...] Dad wasn't [...] but my Mum was [...] Oh man she's made me and my brother's backside black and blue and this is when we didn't have child protection [...] In those days there was nobody you could go to [...] (Harry).

Sexual abuse. The link between early childhood experience and subsequent sex offending is seen most strongly in the context of childhood sexual abuse. Participants talked about their own early sexual engagement in various forms, including one who had a positive childhood attachment but had been both orally and anally abused by his teacher. Three offenders offered insight into those who have been abused becoming an abuser:

[...] So in the orphanage every night [...] they used to take your clothes away and from 8pm to the morning no clothes on because they say you are naked you cannot run away [...] We used to take a collective shower. It doesn't matter if there were 50 people. The ${ }^{\star \star \star \star \star \star \star \star}$ in charge used to come and touch your genitals everything [...] Eventually, I ran away from the orphanage [...] (Ed).

When I was $7[\ldots]$ | was anally and orally raped by a gang of boys from the village where I lived [...] (Alex). 
Childhood histories of those who had been convicted of both internet and contact offences were complex, especially with regard to childhood sex abuse. Although this is in line with the extensive literature on cycle of abuse (Marshall, 1997; Wolf, 1989) it is overly simplistic to see it as the only variable contributing to child sex offending; it does not seem to characterise all child sex offenders.

\subsection{Escalating factors}

Early childhood experiences are integrated into cognitive structures and processing to inform behavioural responses through to adulthood. When participants discussed aspects of their adult life they identified a number of factors which impacted upon the offence process. As the data emerged, these escalating factors were divided into three subcategories: adult attachment problems, personality styles and substance use. Many participants believed that as a result of such issues they became vulnerable and were inclined to meet their needs by other means. However, not all themes were common in across participants.

4.2.1 Adult relationships. Adult relationships were discussed briefly as an introduction and continued to be referred to throughout the interview schedule where the participants considered it to be relevant. Early childhood attachment is thought to serve as the "template" for relationships in adulthood (Marshall, 1989; Marshall and Marshall, 2002). Those who did not evidence negative childhood attachment tended to have had adult attachments. However, they were separated from their long-term partners due to their offences.

One participant referred to rejection in his relationships as a precursor to his offending behaviour and that this gave rise to a need for intimacy with his step-daughter replacing his wife on both a physical and emotional level:

[...] when my daughter died my wife totally blanked me and shut me out her life and things like that, I wanted to be wanted and that's when I turned to my step daughter for comfort. I took it too far [...] (Fred).

Indeed, a common element for all participants was a lack of trust, and difficulty communicating not only with their partners, but with people in general. Because of this they found themselves turning to children to seek acceptance, and intimacy, where interpersonal closeness is only achieved via sexual contact (Ward and Siegert, 2002).

4.2.2 Interpersonal problems. A number of participants described their own mental health prior to offending as unstable, often experiencing depression and anxiety, and lacking control during periods of negative emotional state, feeling that this may have contributed to their offending (Ward and Siegert, 2002):

[...] I was in this weird state of mind; I wasn't in much state of mind at all [...] I was beginning to get very depressed and I think I was probably a psychiatric case for some length of time (Alex).

[...] you know, feeling low, feeling isolated, feeling alone [...] (Charlie).

4.2.3 Substance use. Substance abuse has often been associated with committing sex offences. However, this theme was not prominent in the majority of the sample. However, participants were not directly asked about their substance use. Alcohol consumption frequently emerged as a contextual feature and facilitator, which the individual believed enticed him to seek an outlet for his desire:

You know [...] having a lot of drink gives me more Dutch courage [...] so; I might do some other kind of sexual offence with the drink [...] (Gavin).

\subsection{Offence-related behaviour patterns}

4.3.1 Sexually deviant interest. The most common theme that runs through a number of interviews is sexually deviant interest and its role as part of an escalating process in sex offending against children. It is generally understood that sexually deviant interest reinforces and develops the desire to sexually abuse children (Howitt and Sheldon, 2008):

It's trying to get some sort of sexual thrill [...] the sexual desire is there and it's always looking for an outlet. You know, my half sister was an outlet; the Internet is an outlet [...] (Gavin).

PAGE 116 | JOURNAL OF FORENSIC PRACTICE $\mid$ VOL. 16 NO. 22014 
But I would like to add that basically the connection for Internet and contact offences Fantasies, fantasies [...] Once the fantasies start; I think its dodgy ground for anyone, myself [...] (Charlie). I would come home and use the Internet and start looking at naturist images and I would get sexually aroused over these images but not in public [...] a sudden sexual desire and that sexual desire has stuck with me for life. So those two facts, that sexual desire which is still there and then not recognising I am stepping over the boundary too far is what allowed me to download (Fred).

Some reported becoming bored with routine fantasies and looked for the next big virtual thrill. Their behaviour became more chronic and pronounced, taking riskier and riskier forms. In some cases, the offender moved from viewing low-level indecent images to more and more extreme images in order to feed their arousal. These offenders have also described their sexually deviant fantasies as a motivator to commit contact offences:

I put it into a search engine words like Lolita [...] Lolita sex and all that and certainly to begin with any way [...] I found it very exciting but of course after a while I found that it was a little bit of a fraud. You didn't really [...] find as what you are expecting [...] you didn't find such exciting things as you thought $[\ldots]$ it was much more commercial $[\ldots]$ then I was expecting $[\ldots]$ you know $[\ldots]$ I never joined things like these rings $[\ldots]$ where probably would see $[\ldots]$ really $[\ldots]$ really dodgy materials $[\ldots]$ so $[\ldots]$ after a while [...] I didn't really find those images and everything very exciting [...] which is why I much preferred sending those messages to the seventeen year old because it felt more real [...] you know [...] I could just get sexual thrill masturbation to ejaculation and all that using the Internet [...] I find it quite aesthetically pleasing and to a certain extent arousing [...] but I was definitely moving towards making contact [...] (Gavin).

So these images, I would look at them, oh that's pretty, and then look at the next one. I don't linger, in and out [...] Err, yeah [...] what you're looking at, you're always looking for improvement [...] (Ben).

Sexually deviant interest is primarily of importance in child sex offenders as it facilitates arousal in the course of masturbation or motivation to further offending (Howitt and Sheldon, 2008). The vast majority of those who denied having sexually deviant interest subsequently presented with more offence supportive beliefs, in order to support this claim.

4.3.2 Lack of self-control. Although, without a sexually deviant interest, lack of self-control alone would not determine the process of offending against children, it is the broadest and most commonly found theme for all participants. The components of Gottfredson and Hirschi's (1990) theory were appropriate for many of the participants and a general explanation of all offending could be applicable to their offending behaviour:

I certainly have not had any Internet connection at home since I was arrested in October 2006 [...] I literally haven't had it [...] because I haven't trusted myself to have it. I still wouldn't to this day trust myself to have Internet connection in the flat [...] I just don't have one [...] (Gavin).

[...] and realised the mistake I've made and I thought I didn't want to do that to anyone again but I hate these desires and I knew exactly how to find them on the Internet. So I thought I will give it a try (Fred).

As Aslan (2008) notes, however, the more an offender attempts to suppress unwanted thoughts the more likely it is that unwanted thoughts will resurface:

$[\ldots]$ if I was sober I still feel the Internet connection was there [...] I was on my own [...] in my flat it would still be too much of a temptation to go on [...] perhaps go into a chat site, try and chat up teen girls, talk dirty to them [...] you know ask them [...] sort of thing would be like [...] do you wear a thong and all that [...] so, and I am sure I would still do it [...] I still would be tempted to do it. It would be a little bit like a kid in a candy shop, knowing that there are all those teen girls out there on those chat sites [...] I would be very tempted to go on there and do it. So, I just don't have Internet connection (Gavin).

I have no contact with children. I don't, specifically fantasise about children, although one could do, but I don't, I use adult gay fantasy material and that works for me and it keeps me safe (Charlie).

The indications are that the majority of offenders offend because of a failure to control their sexual desires (Lindsay et al., 2007); however, opportunity must present itself for the offence to occur.

4.3.3 Opportunity. This theme is implicitly present in Finkelhor's (1984) motivation and opportunity to offend precondition wherein he argues that the child sex offender has to be 
motivated to set aside his own inner inhibitions and it is easier for him to do this if he holds a position (formal or informal) in which he is not being monitored:

My wife didn't want to particularly look after her or anything. She was grieving and doing things her own way. So I used to have to get up in the mornings get her breakfast and things like that and I played with her. I would sit and watch television with her and give her cuddles. She was always a very cuddly person so we always used to cuddle. As part of that cuddling I started touching her between the legs (Fred).

It was more originally it was more using with my half sister. It was [...] I suppose about using the fact that she was family and so gave me contact with her [...] enabled me to have contact with her [...] and so I was able to use that [...] I was able to kind of exploit her in that way [...] The opportunity was there and just basically lay with her [...] touched her and then [...] on one occasion attempted to rape her [...] when she was asleep [...] (Gavin).

Once the offender is on a pathway to commit a sexual offence, he spends a considerable amount of time planning and creating opportunities to offend and making use of attractive features of the internet:

I'd known them, they were from a nudist family, a naturist family, I had been a naturist for many years, I met them, I had met their mum and Dad at a naturist place, the same year I met xxx in 1990 and these offences happened, 98, 1997 Or 1998, so l'd known them for seven or eight years by this time, umm, so they were two to four when I first knew them, umm, I had seen them naked hundreds of time, not hundreds, but many times before taking pictures [...] (Alex).

4.3.4 The role of the internet. It is clear that child sex offenders use the internet both to access indecent images and to select victims for abuse (Quayle and Taylor, 2002a). In some instances the former may lead directly to the latter:

So I think if it had not been for the situation I would never have committed the contact offence. Even if the downloading had been predominant I would not have gone on to contact offences because that would have been a step too far. A line I wasn't willing to cross (Fred).

In other instances offenders reported using the internet to access indecent images rather than having actual sexual contact with children:

[...] So I was thinking the Internet will help me relieve myself because I don't want to hurt someone.

So that is where I started (Ed).

The primary aim of accessing, downloading and collecting available stimulus materials on the internet is to increase sexual arousal and fantasy through masturbation, which acts as a substitute for committing further contact offences. Further, the internet enables offenders to access potential victims. With regard to internet use two themes emerged: access to available materials and anonymity.

Access to available materials. Offenders with access to indecent images online talked about the distinctive and appealing characteristics of the internet, which included $24 \mathrm{~h}$ availability:

[...] so this sort of thing was freely available [...] what the Internet found for me, it had everything I wanted. I didn't believe all, you get on the Internet, I didn't believe it, but when I found that it was true that's when I got a computer. I used my computer at work, it gave me an insight that there really was everything was available on the Internet [...] I know the argument, is that if people don't watch it, and then the pictures are not taken. You can say that about anything, supply and demand (Ben).

Indecent images of children are potentially accessible at all times, which afford child sex offenders' greater opportunity to feed their sexual arousal and target children:

Oh, easy access, because, rather than going out and buying a magazine, you can go and push a button and it's there (Ben).

Anonymity. While availability and accessibility make it easier to explore sexuality online, it is the perception of anonymity that poses the most risk (Cooper, 1998). Anonymity encourages deviant sexual acts such as the viewing and downloading of indecent images (Young, 1999) often facilitating the person's confidence to do things that they might not do or say in the real word:

The fact that you are in your own house with no one watching you, reports of the ISPs can't do anything just makes it a safe way of offending and dealing with those desires (Fred).

PAGE 118 | JOURNAL OF FORENSIC PRACTICE $\mid$ VOL. 16 NO. 22014 
Easy access to available materials and anonymity are very powerful qualities that serve to heighten the attractiveness of the internet for individuals who have an interest in acquiring and disseminating indecent images.

4.3.5 Cognitive distortions. Whilst developmental background and escalating factors play a fundamental role, it is through cognitive distortions that offenders avoid accepting responsibility for their offences. Such distortions serve a self-protective function by reducing anxiety, guilt or shame associated with their offending. This was the most common theme, found for all offenders with evidence for five sub themes: justifications, denial, normalisation, blame and minimisation.

Justifications. Justifying their behaviour as misunderstood was frequently referred to. They look for other explanations that will "deny their sexually deviant acts" as effectively as possible. However, because sex offending is a behaviour that is very difficult to justify, offenders who attempt to justify their acts may select their explanations based on socially acceptable causes of reprehensible behaviour:

So I lived with my wife for nearly 27 years and never had any sex so I used to masturbate a lot [...] She stopped having sex when my daughter was born in 1982. Since 1982 I have not had any physical contact with anyone. Do you know a lot of people who have stayed like that? I was faithful to her. So I start to mess around on the computer. I started to take pleasure from this. What's wrong and what's right at the time I don't think about it (Ed).

Denial. Many offenders convicted of downloading indecent images of children denied that the primary function of their involvement was for sexual use, while those involved in contact offences were more prepared to take responsibility for their offences:

I didn't download any pictures and I didn't, err, over five years, err that I had them, I only looked at them about three times, I kept them downstairs in a garage in a box and it was extremely difficult to get the bloody things up, so I didn't even use them for masturbatory effects or anything like that, I'd just taken them over an eight to nine month period (Alex).

Some offenders spoke of accidentally accessing indecent images on the internet:

[...] I didn't know what I was down loading. Basically, l'd never had a computer and l'd never seen the Internet [...] I down loaded these images blind; all I saw was the menus. I down loaded the menus. Got a virus in my computer and was never able to look at them (Ben).

Other offenders described their viewing of indecent images as harmless, creating the impression that no one gets hurt:

If it is on the computer it is on the computer but I never hurt anybody (Ed).

Normalisation. There was a pervasive impression from the participants that what they were doing was normal and that a large number of other people engaged in the same behaviours:

You're naked, surely people have got pictures of their children in the bath playing with a duck or whatever you know what I mean. I used to have a duck me. But what I am saying you must have pictures like that, the first time baby sits up in the bath, its first bath. It can be classed as indecent if people wanted to [...] I didn't find them as offensive as some other people found them [...] Erm [...] having something nude just stood there, I could not find it offensive (Harry).

Blame. A number of the interviews identified attributing responsibility for offending behaviour to someone or something else as a common belief used to excuse sexual activity with children.

Attributing blame and responsibility to the victims was a common theme:

I know from that youngsters can take the lead and there was never erm, it was a one way thing in a sense, I never forced him to do anything for myself I'd had a sort of dysfunctional problem [...] I never forced child in the sense in some respects worse for myself that I controlled them or cajoled them or whatever into going along with this and then satisfied myself by saying it was what the child wanted as well (David).

Others blamed the technology or other factors to excuse or explain their actions:

Because I got a virus on my computer, I didn't look at my computer for a year. What I down-loaded, what I printed, I printed at work, but that wasn't children, that was adults and that was what appealed to me and that was it basically (Ben). 
I wanted to take pictures of xxx. I thought I was going to die, I really did, I'd had a stroke, I was told this was usually the pre-curser to a bigger one [... ] I've got a complete absolute blank, I think it's a result of the stroke, well I know it's a result of the stroke, because l've got patches in my memory as well [...] I think it was a result of the frustration and everything else and me putting a lot of weight on, drinking and everything. And I was in this weird state of mind; I wasn't in much state of mind at all (Alex).

Minimisation. Many offenders who admitted significant details of their offences still minimised the overall seriousness of their behaviour:

[...] Apparently I had twenty-two thousand images on my computer [...] they (police) found on the data base, only fifteen were considered children, they talk about children in legal terms which is under eighteen, in my mind a child is a child, as a youngster, I had two young girls of my own, so, umm [...] I mean, children, to my mind a child can give me nothing sexually that an adult can't, in fact, another anomaly, a woman matures sexually much later than a boy, the male is, more receptive (?) the girls not started yet, we're sort of running out of steam when they're getting randy. So I could see no sexual attraction to a child, because that, my pleasure in sex was given pleasure, from the things I read, because, they call it pornography, but, it was literature, rather than photographic [...] (Ben).

In sum, lack of self-control is a central problem for many child sex offenders who spend a considerable amount of time creating opportunities and making use of the internet to access available stimulus materials while retaining anonymity. The internet provides stimulation for their fantasy development, and potentially access to victims if their sexual needs are no longer being met by images alone. Their actions seem to be facilitated by the internet (before and after contact offences) and the constant evolving validation of their actions by cognitive distortions.

\section{Discussion}

There are both differences and similarities between the themes which emerged from the present study and themes emphasised in theories of the offence process (e.g. Gottfredson and Hirschi, 1990; Ward and Hudson, 1998; Wolf, 1989). Two primary themes were generated relating to offenders' childhood attachment difficulties and experiences of childhood abuse. Escalating factors centred around three themes: adult relationships, personality problems and substance use. Five further main categories involving both explanatory and maintaining factors were also identified: lack of self-control, opportunity, the role of the internet, sexually deviant interests and cognitive distortions.

The results suggest the importance of negative developmental experiences not only with regard to poor parental relations but also in relation to emotional, physical and sexual abuse experiences. This is in line with Middleton et al. (2006) finding that there were no differences between internet and contact offenders in their early attachment experiences which led them to develop personality problems in adulthood. Similarly, Howitt and Sheldon (2007) report that both internet and contact offenders were fairly similar with regards to experiencing poor bonding with their parents. However, some participants in the current study reported positive attachment experiences suggesting that negative developmental experiences are likely to provide an explanation for the sexually deviant behaviour of only some individuals.

With regard to the five etiological pathways suggested by Ward and Siegert's (2002) model only intimacy deficits and emotional dysregulation seemed to be implicated as possible contributory factors to offending. However, the focus of the model was on the initial development and onset of sexual offending rather than the issue of maintenance or exacerbation which may relate to other factors.

Lack of self-control was a central factor across all participants; this is an aspect commonly reported in general theories of crime. It has been argued that lack of self-control emerges as a result of early childhood experiences, failures in education and social relationships (Gottfredson and Hirschi, 1990). Individuals lacking in self-control tend to be impulsive, engage in risk taking behaviours and are less empathic. The extant empirical literature suggests that regardless of the methodology utilised, lack of self-control is predictive of many forms of sexually deviant behaviour, including internet child sex offences (Lussier et al., 2005). While lack of self-control may underlie offending behaviour, it does not explain the likelihood that one type of offence might be committed rather than another.

PAGE $120 \mid$ JOURNAL OF FORENSIC PRACTICE $\mid$ VOL. 16 NO. 22014 
The second escalating theme to emerge relates to opportunity to offend. As a result of poor self-control, offenders are more likely to act on opportunities that present themselves; in the case of child sex offenders this will be sexual behaviours that are easy to commit, provide immediate sexual pleasure and minimise the possibility of detection. Attractive opportunities combined with lack of self-control capture the simultaneous influence of internal and external restraints on behaviour which may then form the necessary and sufficient conditions for sexual offending to occur. In line with Ward and Hudson's (1998) proposition, in the present sample the offenders were employing active strategies (the approach-explicit pathway), were constantly seeking opportunities to offend, and were purposefully manipulating their environment to set-up such offences with potential victims identified through the internet. For example, where the offender accesses indecent images to enhance sexual fantasy and arousal, they may well be waiting to encounter the right situation and opportunity to act on it. In these cases of premeditated opportunism, the situational cues trigger the acting out.

Accessing available stimulus materials, while remaining anonymous on the internet, presents an attractive opportunity to those lacking in self-control. This is consistent with Quayle and Taylor's (2003) theoretical model. In their study participants reported that their emerging sense of power and control was aided by their online anonymity. This is also in line with Cooper's (1998) argument that the internet has created an omnipresent avenue for those with a deviant sexual interest, facilitating the acquiring, reproducing and disseminating of indecent images of children. It is also consistent with Davis's (2001) Model of Pathological Internet Use, which assumes that internet use becomes like an addiction over which the user has little control. Clearly, planning and preparation to create opportunities goes into the downloading behaviour of many convicted offenders. Initially they seem to try and control the risks and consequences involved in their offending behaviour but when the online fantasies no longer meet their sexual needs, and when an opportunity arises, they may then go on to commit contact offences. However, for which internet offenders this becomes and issue and what factors may prompt some internet offenders to commit contact offences whilst others do not raises a central issue for future research. Some offenders had fairly ready access to children, either because victims were well known to them or because they had occupations that gave them opportunity to sexually abuse and avoid detection and this also warrants further investigation.

Deviant sexual interest towards children is thought to play an important role in motivating and maintaining sexual offending. Marshall et al. (1991) found that 52 per cent of the child sex offenders admitted to fantasising about children, and 22 per cent indicated that their first deviant sexual fantasies occurred prior to committing their first sex offences. This finding is in line with Ward and Beech's (2006) model that among numerous clinical problems such as emotional dysregulation, social difficulties and cognitive distortions, deviant sexual interest is a primary causal factor for sex offences. The current interviews suggest that use of the internet is related to deviant sexual preferences. This is consistent with theoretical explanations of offending behaviour patterns of internet offenders (Quayle and Taylor, 2002a; Howitt and Sheldon, 2008) which argue that the internet encourages the translation of fantasy into behaviour. Deviant fantasies promote the need for internet use, which then promotes deviant behaviour. In other words, sexually deviant fantasies are highly related to the actual commission of sexual offences and the internet potentially affects both fantasies and actual sexual behaviours.

Finally, the interviews suggest that cognitive distortions play an important role in offending behaviour. The cognitive distortions documented fell into five main categories that relate to beliefs of justifying sexual acts with children, normalising, blaming external and internal factors, denying and minimising the harm caused by sexual activity between an adult and a child. These distortions were concentrated in pre-offence and post-offence stages. During the pre-offence stage, they relate to the offender's tendency to overcome inhibitions to offend, whereas during the post-offence stage, they serve to minimise negative emotional effects and maintain the offenders positive self-image. The content of cognitive distortions reported in the interviews is broadly consistent with previous research with sex offenders (Burke et al., 2002; Quayle and Taylor, 2003; Howitt and Sheldon, 2007) as well as with research suggesting that cognitive 
distortions contribute to the offence process, promoting further offences through justifications of the acts (Ward and Hudson, 1998; Wolf, 1989; Eldridge, 1998).

Offenders who have convictions of both downloading indecent images and contact offences may well fit the profile of Moffitt's (1993) chronic and life-course persistent patterns of criminal behaviour. Offenders may also be considered to be both situational and preferential offenders (Lanning, 2001) as they continued to access abusive images of children to satisfy their deviant interests. These offenders offend against a child through opportunity or sometimes purposely target children in their online activity.

\subsection{Limitation of the study}

Although this research provides valuable insight into child sex offenders who both download indecent images of children and commit contact offences, it is not without its limitations. First, the sample studied consisted of only a small group of male child sex offenders who were supervised by London Offender Management Units in the community. Restricting the study to these offenders means that the findings may not apply to child sex offenders from other probation groups or from prison populations. It is also well documented in the literature that convicted sex offenders represent only the tip of the iceberg as the majority of sex offences remain undetected (Abel and Rouleau, 1990). Convicted sex offenders may not be representative of individuals who have sexually deviant interest but have not been convicted.

As with most research in this field the participants were men who had been convicted of child sex offences. However, there is evidence of a wide variety of sexual offences known to have been committed by females, either independently or with a male perpetrator and a number of differences between the treatment of male and female sex offenders have been well established. Therefore, the findings would not provide a complete picture for female sex offenders. Also the eight men were from a relatively older age group (40-65) and it is possible that the results may not be applicable to offenders of other ages. For example, a sample of young adult committing internet sex offences could exhibit different patterns.

Finally, there are only minimal ways of confirming or validating the interview responses. A problem with "social desirability" may exist in face-to-face interviews as the sex offender may be attempting to please or otherwise mislead the researcher. However, verification of their accounts against probation files indicated that there was little deviation from the facts of the offences. In some cases, offenders provided rich detail about the context of their offences, which was often missing from both sources of official accounts. All participants were asked about offences that they have been reported as having committed; either recorded as convictions (MG16) or recorded in offenders' probation files (eOASys) as a current offence.

\subsection{Recommendations for future research and implications for practice}

Research on sex offenders emphasises the role of personal factors (e.g. personality, implicit theories) leading to the commission of internet sex offences but often neglects the role of situational factors highlighted in this research which might lead to the committing of contact offences. Offenders with "the world is a dangerous place" theory believe that their social world is excessively hostile, filled with individuals who are likely to exploit and reject them at any opportunity. Ward and Keenan (1999) speculate that this theory results from early and continued physical and emotional abuse, where offenders learn to take measures to avoid harm or to satisfy their needs and desires'. Future research exploring situational factors in rather more detail as well as individual characteristics previously identified in the sexual offending literature would provide a more comprehensive description of the offending process of internet-contact offenders. It is possible that the flexibility afforded by Wikström's (2006) Situational Action Theory could provide a theoretical grounding for those attempting to understand the diversity of sexual offenders, considering both external and internal causes from a proximal and distal perspective within an integrated framework.

Future research could usefully include data from a larger sample of probation and prison populations comparing responses of internet-contact child sex offenders with internet only or contact offenders in order to identify variations in patterns of offending behaviour.

PAGE 122 | JOURNAL OF FORENSIC PRACTICE | VOL. 16 NO. 22014 


\section{The current research also offers a number of implications for practice}

- Understanding the offence process would enable clinicians to better understand the rationale behind the actions of offenders and in turn, better address some areas of treatment intervention in order to prevent re-offending (Ward and Hudson, 1998).

- It is suggested that treating professionals should focus on the motive or function of the internet use, in order to identify more individualised case formulation prior to treatment.

- In current practice, offenders who have convictions for both internet and contact offences are assessed as very high risk and of high sexual deviance and are typically treated on programmes which are designed to address the empirically determined needs for contact offenders. It is proposed that there is a need for developing wider treatment programmes that target more diverse offending behaviours.

- The findings from this study could be used as a guide to structure more effective assessment tools specific to internet-contact child sex offenders. This may ultimately help in the construction of offending behaviour treatment programmes that are more responsive to the needs and issues faced by these offenders.

\section{References}

Abel, G.G. and Rouleau, J.L. (1990), "The nature and extent of sexual assault”, in Marshall, W.L., Laws, D.R. and Barbaree, H.E. (Eds), Handbook of Sexual Assault: Issues, Theories, and Treatment of the Offender, Plenum, New York, NY, pp. 9-12.

Aronson, J. (1994), "A pragmatic view of thematic analysis”, Qualitative Report, Vol. 2 No. 1, pp. 1-3.

Aslan, D. (2008), "The psychological aspects of coping with being accused of sexual offences", British Journal of Forensic Practice, Vol. 10 No. 4, pp. 19-37.

Baumeister, R.F. and Boden, J.M. (1998), "Aggression and the self: high self-esteem, low self-control, and ego threat", in Geen, R.G. and Donnerstein, E. (Eds), Human Aggression: Theories, Research, and Implication for Social Policy, Academic Press, New York, NY, pp. 111-38.

Beech, A.R. and Mitchell, I.J. (2005), "A neurobiological perspective on attachment problems in sexual offenders and the role of selective serotonin re-uptake inhibitors in treatment of such problems", Clinical Psychology Review, Vol. 25 No. 2, pp. 153-82.

Beech, A.R., Fisher, D.D. and Beckett, R.C. (1999), "An evaluation of the prison sex offender treatment programme”, UK Home Office Occasional Report, London, available at: www.homeoffice.gov.uk/rds/pdfs/ occ-step3.pdf (accessed 21 June 2010).

Braun, V. and Clarke, V. (2006), "Using thematic analysis in psychology”, Qualitative Research in Psychology, Vol. 3 No. 2, pp. 77-101.

Breakwell, G.M., Hammond, S. and Fife-Schaw, C. (2000), Research Methods in Psychology, Sage Publications, London.

Briggs, F. and Hawkins, R.M.F. (1996), "A comparison of the childhood experiences of convicted male child molesters and men who were sexually abused in childhood and claimed to be non-offenders", Child Abuse and Neglect, Vol. 20 No. 3, pp. 221-34.

Burke, A., Sowerbutts, S., Blundell, S. and Sherry, M. (2002), "Child pornography and the internet: policing and treatment issues", Psychiatry, Psychology and Law, Vol. 9 No. 1, pp. 79-84.

Connolly, M. (2004), "Developmental trajectories and sexual offending: an analysis of the pathways model", Qualitative Social Work, Vol. 3 No. 1, pp. 39-59.

Cooper, A. (1998), "Sexuality and the internet: surfing into the new millennium", Cyber Psychology and Behaviour, Vol. 1 No. 2, pp. 187-93.

Davis, R.A. (2001), "A cognitive-behavioural model of pathological internet use", Computers in Human Behaviour, Vol. 17 No. 1, pp. 187-95.

Eldridge, H. (1998), Therapist Guide for Maintaining Change: Relapse Prevention for Adult Male Perpetrators of Child Sexual Abuse, Sage, London. 
Fergusson, D.M., Lynskey, M.T. and Horwood, L.J. (1996), "The comorbidity between affective disorders and nicotine dependence in a cohort of 16 year olds”, Archives of General Psychiatry, Vol. 53 No. 11, pp. 1043-7.

Finkelhor, D. (1984), Child Sexual Abuse: New Theory and Research, The Free Press, New York, NY.

Gilbert, N. (1993), Researching Social Life, Sage, Thousand Oaks, CA.

Gottfredson, M. and Hirschi, T. (1990), A General Theory of Crime, Stanford University Press, Palo Alto, CA.

Howitt, D. and Sheldon, K. (2007), "The role of cognitive distortions in paedophilic offending: internet and contact offenders compared”, Psychology, Crime, and Law, Vol. 13 No. 5, pp. 469-86.

Howitt, D. and Sheldon, K. (2008), "Sexual fantasy in paedophile offenders: can any model explain satisfactorily new findings from a study of internet and contact sexual offenders?", Legal and Criminological Psychology, Vol. 13 No. 1, pp. 137-58.

Jeglum-Bartusch, D., Lynam, D.R., Moffitt, T.E. and Silva, P.A. (1997), "Is age important: testing general versus developmental theories of antisocial behaviour", Criminology, Vol. 35, pp. 13-48.

Lahey, B.B. and Waldman, I.D. (2003), "A developmental propensity model of the origins of conduct problems during childhood and adolescence", in Lahey, B.B., Moffit, T.E. and Caspi, A. (Eds), Causes of Conduct Disorder and Juvenile Delinquency, Guilford, New York, NY, pp. 76-117.

Lambert, S. and O'Halloran, E. (2008), "Deductive thematic analysis of a female paedophilia website", Psychiatry, Psychology and Law, Vol. 15 No. 2, pp. 284-300.

Lanning, K.V. (2001), "Child molesters and cyber paedophiles: a behavioural perspective", in Hazelwood, R. and Burgess, A.W. (Eds), Practical Aspects of Rape Investigation: A Multidisciplinary Approach, 3rd ed., CRC Press, Boca Raton, FL, pp. 199-220.

Lindsay, W.R., Ward, T., Morgan, T. and Wilson, I. (2007), "Self-regulation of sex offending, future pathways and the Good Lives Model: applications and problems”, Journal of Sexual Aggression, Vol. 13 No. 1, pp. 37-50.

Lussier, P., Proulx, J. and Leblanc, M. (2005), "Criminal propensity, deviant sexual interests and criminal activity of sexual aggressors against women: a comparison of explanatory models", Criminology, Vol. 43 No. 1, pp. 249-59.

Mann, R. and Beech, A.R. (2003), "Cognitive distortions, schemas and implicit theories", in Ward, T., Laws, D.R. and Hudson, S.M. (Eds), Theoretical Issues and Controversies in Sexual Deviance, Sage, London, pp. 135-53.

Marshall, W.L. (1989), "Invited essay: intimacy, loneliness and sexual offenders", Behaviour Research and Therapy, Vol. 27 No. 5, pp. 491-503.

Marshall, W.L. (1997), "Pedophilia: psychopathology and theory", in Laws, D.R. and O'Donohue, W. (Eds), Sexual Deviance: Theory, Assessment, and Treatment, The Guilford Press, New York, NY, pp. 164-83.

Marshall, L.E. and Marshall, W.L. (2002), "The role of attachment in sexual offending: an examination of preoccupied attachment style offending behaviour", in Schwartz, B.K. (Ed.), The Sex Offender: Current Treatment Modalities and Systems Issues, Civic Research Institute, Kingston, NJ, 3-7.

Marshall, W.L., Barbaree, H.E. and Eccles, A. (1991), "Early onset and deviant sexuality in child molesters", Journal of Interpersonal Violence, Vol. 6 No. 3, pp. 323-36.

Middleton, D., Elliot, I.A., Mandeville-Norden, R. and Beech, A.R. (2006), "An investigation into the applicability of the Ward and Siegert Pathways Model of child sexual abuse with internet offenders", Psychology, Crime and Law, Vol. 12 No. 6, pp. 589-603.

Moffitt, T. (1993), "Adolescent-limited and life-course persistent antisocial behaviour: a developmental taxonomy", Psychological Review, Vol. 100 No. 4, pp. 647-701.

Orford, J. (1996), "Qualitative research for applied psychologists", Clinical Psychology Forum, Vol. 1, pp. $19-26$.

Patterson, G.R. and Yoerger, K. (2002), "A developmental model for early- and late-onset delinquency", in Reid, J.B., Patterson, G.R. and Snyder, J. (Eds), Antisocial Behaviour in Children and Adolescents: a Developmental Analysis and Model for Intervention, American Psychological Association, Washington, DC, pp. 147-72.

Quayle, E. and Taylor, M. (2002a), "Child Pornography and the internet: perpetuating a cycle of abuse", Deviant Behaviour, Vol. 23 No. 4, pp. 331-61.

PAGE 124 | JOURNAL OF FORENSIC PRACTICE | VOL. 16 NO. 22014 
Quayle, E. and Taylor, M. (2003), "Model of problematic internet use in people with a sexual interest in children", Cyber Psychology and Behaviour, Vol. 6 No. 1, pp. 93-106.

Sheldon, K. and Howitt, D. (2007), Sex Offenders and the Internet, John Wiley and Sons, Chichester and West Sussex.

Thompson, R.A. (1994), "Emotional regulation: a theme in search of definition", in Fox, N.A. (Ed.), The Development of Emotion Regulation: Biological and Behavioural Considerations, Monographs of the Society for Research in Child Development, University of Chicago Press, Chicago, Vol. 59 No. 240, pp. $25-52$.

Ward, T. and Beech, A.R. (2006), "An integrated theory of sexual offending", Aggression and Violent Behaviour, Vol. 11 No. 1, pp. 44-63.

Ward, T. and Hudson, S.M. (1998), "The construction and development of theory in the sexual offending area: a meta-theoretical framework”, Sexual Abuse: A Journal of Research and Treatment, Vol. 10 No. 1, pp. 47-63.

Ward, T. and Keenan, T. (1999), "Child molesters' implicit theories", Journal of Interpersonal Violence, Vol. 14 No. 8, pp. 821-38.

Ward, T. and Siegert, R.J. (2002), "Toward and comprehensive theory of child sexual abuse: a theory knitting perspective", Psychology, Crime, and Law, Vol. 8 No. 4, pp. 319-51.

Ward, T., Hudson., S.M. and Marshall, W.L. (1996), "Attachment style in sex offenders: a preliminary study", The Journal of Sex Research, Vol. 33 No. 1, pp. 17-26.

Wikström, P.O.H. (2006), "Individuals, settings and acts of crime", in Wikström, P.O.H. and Sampson, R.J. (Eds), The Explanation of Crime: Contexts, Mechanisms and Development, Cambridge University Press, Cambridge, pp. 61-107.

Willig, C. (2001), Introducing Qualitative Research in Psychology: Adventures in Theory and Method, Open University Press, Buckingham.

Wolf, S.C. (1989), "A model of sexual aggression/addiction”, Journal of Social Work and Human Sexuality, Vol. 7 No. 1, pp. 131-48.

Young, K.S. (1999), "The evaluation and treatment of internet addiction”, in VandeCreek, L. and Jackson, T. (Eds), Innovations in Clinical Practice, Professional Resource Press, Sarasota, FL, Vol. 17, pp. 19-31.

\section{Appendix. Description of participants}

Demographic and offence details of the participants were collected from offender's probation files. All names and certain details have been changed to protect anonymity.

Alex is a 60-year-old white British man, who has an extensive previous history of sexual offences against children (gross indecency with children, making and possession of indecent photos of a child and publishing obscene articles). When he was aged seven he was anally and orally raped by a gang of boys from the village where he lived. He was also subject to further sexual abuse by two different adult women during his formative years. He has had a number of long-term relationships with adult women. He was married at the age of 21 and had a son with his wife. Currently, he is divorced and lives in a probation hostel.

Ben is a 60-year old white British man, who has been convicted of the making and possession of indecent images of children. He has a previous conviction of sexually abusing his own daughter when she was 11 years old. Ben is divorced and has lived on his own for a number of years. He has three adult children who live independently and with whom he has no contact. There is no known history of childhood maltreatment.

Charlie is a 55-year-old white British man, who was found guilty of possession of indecent images of children. He has previous convictions for contact offences against boys for whom he had a pastoral responsibility in his role as a teacher. He disclosed being sexually abused by his music teacher. He was in a relationship with a man he met through an internet dating site but currently, he is single and lives in a family home.

David is a 61-year-old white British man, who pleaded guilty to the indecent assault of children and the making and possession of indecent images of children. There is a history of childhood 
sexual abuse at the age of 12 . He was married for 23 years but was divorced prior to his arrest. He has no children and lives in a probation hostel.

Ed is a 60-year-old white European man, who has been convicted of causing a child aged 15 to watch a sexual act using the MSN programme and downloading and possession of indecent images of children. He has been married for almost 30 years although he has not had a sexual relationship with his wife since she gave birth to their daughter 27 years ago. He is separated from his wife and lives alone in rented accommodation. There is evidence of childhood sexual abuse. He was placed in an orphanage by his mother when he was six years old and was subjected to sexual abuse by older children there.

Fred is a 44-year-old white British man with the index offence of making, possessing and distributing indecent images of children. He was also convicted of indecent assault on his step-daughter when she was approximately eight years old and indecent assault against his son. As a result of his offending, he is estranged from his wife, who is the mother of the victim of the sexual assault, and of his son. He is currently divorced and residing in a supported housing project for sex offenders.

Gavin is a 43-year-old white British man, who has pleaded guilty to making indecent images of children with a further charge of sending inappropriate text messages with sexual content to a child. He also has a previous conviction for Attempted Rape and Indecent Assault on a female under 16. The victim was his half sister who was eight years of age when the first offences were committed. He is single and has never had a relationship with an adult woman. There is no indication of childhood maltreatment.

Harry is a 56-year-old white British man, who has been found guilty of possessing an indecent image of a child. He has a previous conviction for sexually assaulting a female under the age of 16 . There is a history of emotional and physical abuse at the hands of his mother. Harry was married in the 1980s and had three children with this partner. However, subsequent to their divorce his ex-wife gained an injunction against him; as a result of this he has not seen his children since 1988. He lives alone in a two bedroom flat.

To purchase reprints of this article please e-mail: reprints@emeraldinsight.com Or visit our web site for further details: www.emeraldinsight.com/reprints 